\title{
The Effect of Drying Parameters on the Quality of Pork and Poultry-Pork Kabanosy Produced according to the Traditional Specialties Guaranteed Recipe
}

\author{
Marta Chmiel, Lech Adamczak, Katarzyna Wrońska, \\ Dorota Pietrzak, and Tomasz Florowski \\ Division of Meat Technology, Department of Food Technology, Faculty of Food Sciences, \\ Warsaw University of Life Sciences-SGGW, 166 Nowoursynowska Street, 02-787 Warsaw, Poland \\ Correspondence should be addressed to Marta Chmiel; marta_chmiel@sggw.pl
}

Received 12 January 2017; Revised 6 April 2017; Accepted 19 April 2017; Published 28 May 2017

Academic Editor: Maria J. Fraqueza

Copyright (C) 2017 Marta Chmiel et al. This is an open access article distributed under the Creative Commons Attribution License, which permits unrestricted use, distribution, and reproduction in any medium, provided the original work is properly cited.

\begin{abstract}
The aim of this study was to determine the effect of differentiated air relative humidity during the drying process on selected quality features of TSG (traditional specialties guaranteed) pork and poultry-pork kabanosy. After heat treatment and 24-hour cooling at $4-6^{\circ} \mathrm{C}$, the products were placed in three chambers at $15^{\circ} \mathrm{C}$ with differentiated air relative humidity: 60,70 , and $80 \%$, respectively. The drying process was carried out until all variants of kabanosy achieved the required final yield of the product $(<68 \%)$. Color components, water activity and shear force, water, protein, fat, and salt content, and the TBARS indicator values were determined. The drying process might be shortened ( $50 \%)$ by a reduction of humidity in the drying chamber from 80 to $60 \%$. The changes in the content of chemical components in pork kabanosy compared to poultry-pork ones demonstrated the different dynamics of the drying of the two types of kabanosy and the need for the selection of optimum drying conditions relative to raw material composition.
\end{abstract}

\section{Introduction}

Sausages are one of the oldest meat products and have been manufactured for nearly two thousand years. They are consumed all over the world due to their attractive flavor profile. Dry and semidry sausages are considered by consumers to be two of the most delicious and highly sought after products [1-3]. The growing interest in this type of products results from their diversity, the use of different raw materials, and their degree of fragmentation, not to mention the spices or smoking methods used. Moreover, their high desirability is also affected by their unique taste and aroma $[4,5]$. In recent years, there has been an increase in consumer demand in terms of food quality and its safety and effects on health [6]. Growing consumer interest has been noted in food with a smaller level of additives [7], as well as traditional and natural products, especially in the countries of Eastern Europe [8, 9]. This group of products includes kabanosy, which are popular in Poland. Kabanosy are a Polish traditional product whose production history dates to the 1920s/30s [10]. The word "kabanos" probably comes from the name of the pork, "kabanina," which was obtained from a characteristic species of pig, known as a "kaban." In the nineteenth century, a kaban in Poland and Lithuania was a young male, extensively fattened with potatoes to obtain a delicate meat with a high degree of intramuscular fat (marbled meat with intramuscular fat content above 3\%), which in turn positively affected its juiciness and tenderness. In 2011, pork kabanosy were registered in the European Union as a product of traditional specialties guaranteed (TSG). Kabanosy are long, thin, and evenly wrinkled pork sausages in natural casings, sheep intestines. The product is subjected to drying and smoking processes, which affects the formation of their specific color. The color of the surface of pork kabanosy should be dark red with a hint of cherry, while slightly creamy fat particles and dark red meat pieces should be visible in the cross section [10]. In the case of poultry kabanosy, the color is lighter, which is the result of the use of poultry meat. Kabanosy should 
be characterized by the aroma of cured meat with a delicate hint of cumin and black pepper. The characteristic feature of kabanosy is their unique smell, which is mainly due to smoking.

The drying process also plays an important role in the distinctive, unique taste of kabanosy, emphasizing the advantages of their aroma and taste. Drying is one of the oldest methods of food preservation [11-16]. According to European Parliament and Council Regulation (EU) number 1044/2011 [10], pork kabanosy (TSG) should be dried for 3 to 5 days at a temperature of $14-18^{\circ} \mathrm{C}$, with an air relative humidity of $80 \%$, to achieve the desired yield $(\leq 68 \%)$. The drying process significantly affects the quality of the produced kabanosy and is a highly energy-consuming step that determines the economy of production [11, 14]. Therefore, one aim of this study was to determine the effect of differentiated air relative humidity in the drying chamber $(80,70$, and $60 \%)$ on the quality of pork kabanosy. The consumption of poultry meat has increased rapidly all over the world in the last decade, and poultry production has become the fastest growing meat sector [17]. Due to the nutritional value and low price of poultry meat resulting from its high supply, we also decided to produce poultry-pork kabanosy with a chemical composition similar to pork kabanosy TSG in this study.

\section{Materials and Methods}

2.1. Kabanosy Production. The basic raw materials for the production of pork kabanosy were class I pork, $30 \%$; class IIA, $40 \%$; class IIB, $30 \%$. In the case of poultry-pork kabanosy, the composition was chicken thigh meat, $80 \%$ and pork jowl, $20 \%$. For both types of kabanosy, the same spice composition was used (with respect to raw materials), that is, black pepper $(0.15 \%)$, sugar $(0.20 \%)$, nutmeg $(0.05 \%)$, and cumin $(0.07 \%)$. Pork and poultry-pork kabanosy were produced in three series with precut (pieces measuring $5 \mathrm{~cm}$ ), cured ( $2 \%$ based on the weight of raw materials for 24 hours before production, under refrigeration $4-6^{\circ} \mathrm{C}$ ) pork or poultry meat and pork jowl. The production process was conducted according to the following scheme:

(i) Grinding: class I pork meat or part of chicken thigh meat (30\%) was ground on a mesh of $\varnothing 10 \mathrm{~mm}$; class IIA, IIB pork meat, part of chicken thigh meat (50\%), and jowl were ground on a mesh of $\varnothing 8 \mathrm{~mm}$; the raw material grinding was conducted in a Mesko WN60 laboratory grinder (Mesko-AGD, SkarżyskoKamienna, Poland).

(ii) Mixing: ground meat was mixed using a Kenwood Major mixer (Kenwood, Havant, UK) for 5 minutes to thoroughly mix the ingredients; the spices were added during the mixing.

(iii) Bar stuffing and molding: sheep intestines (Ø $22 \mathrm{~mm})$ were filled using a Dick manual stuffer (Friedr, Dick GmbH \& Co. KG, Deizisau, Germany) and then formed into $25 \mathrm{~cm}$ bars.

(iv) Settling: the bars were deposited on a smoking stick for 1 hour at room temperature. (v) Heat treatment: kabanosy were dried in a Jugema smoking-cooking chamber (Jugema, Środa Wielkopolska, Poland) for 15 minutes at $40^{\circ} \mathrm{C}$, smoked with warm smoke for 30 minutes at $50^{\circ} \mathrm{C}$, and then baked at $75^{\circ} \mathrm{C}$ until $70^{\circ} \mathrm{C}$ was reached in the geometric center of the bar; after the treatment, kabanosy were cooled for 1 hour in an off chamber.

(vi) Cooling: kabanosy were cooled in a refrigerator for 24 hours at $4-6^{\circ} \mathrm{C}$.

(vii) Drying: kabanosy were divided into three variants, and these were subjected to a drying process in a laboratory drying chamber (PHU Chłodnictwo, Warsaw, Poland) at three different drying air relative humidities $(\mathrm{K} 1-80 \% \pm 2 \%, \mathrm{~K} 2-70 \% \pm 2 \%$, and $\mathrm{K} 3-60 \% \pm$ $2 \%)$ at the same temperature of $15^{\circ} \mathrm{C} \pm 2^{\circ} \mathrm{C}$. The humidity and temperature in the chambers were monitored using data loggers (EL-USB-2 models, Lascar Electronics Ltd., Erie, USA). The drying process was carried out until all variants of kabanosy achieved the TSG required [10] final yield of the product, that is, below $68 \%$. The final yield was controlled each $12 \mathrm{~h}$ of the drying process. For kabanosy dried in a chamber at $60 \%$ humidity, the required final yield below $68 \%$ was achieved after $24 \mathrm{~h}$ of the process; at a humidity of $70 \%$ after $36 \mathrm{~h}$; and at a humidity of $80 \%$ after $48 \mathrm{~h}$ of drying.

Before and after the drying process, a range of measurements were performed for each of the three production series, for each of the three variants of kabanosy, and for both pork and poultry-pork ones. The color components $L^{*}, a^{*}, b^{*}$ of the surface and cross-sectional area of the bar, water activity $\left(a_{w}\right)$, and the texture, that is the shear force (only after the drying process), were measured on the unground kabanosy. Ground kabanosy (laboratory grinder Zelmer Diana 886.8, Zelmer, Rzeszow, Poland, grid hole diameter $3 \mathrm{~mm}$ ) were subjected to the measurements of basic chemical component content, that is, water, protein, fat and salt, and the TBARS indicator was also determined.

2.2. Kabanosy Yield at Different Stages of the Production Process. The yield of heat treatment after 24 hours and the final yield after the drying process at different air humidities in the chamber at a level of 80,70 , and $60 \%$, respectively, were determined during the process of pork and poultry-pork kabanosy production. The yields were determined relative to the initial weight before the heat treatment.

2.3. Measurement of Color Components on the $L^{*} a^{*} b^{*}$ Scale. The measurements of color components were performed using a Minolta CR-200 camera (Konica Minolta, Wroclaw, Poland, light source D65, $2^{\circ}$ observer, measuring head hole $8 \mathrm{~mm}$ ) calibrated according to white standard ( $L^{*} 97.81$, $\left.a^{*}-0.45, b^{*} 1.88\right)$. The measurements were taken in each of the 5 repetitions on the surface and cross section of kabanosy, taking the average as a result of the measurement.

2.4. Content of the Basic Chemical Components. The moisture content was determined according to PN-ISO 1442:2000 [18] 
TABLE 1: Yield of kabanosy at different stages of the production process.

\begin{tabular}{|c|c|c|c|c|c|}
\hline \multirow{2}{*}{ Kabanosy } & \multirow{2}{*}{ Thermal treatment yield (\%) } & \multirow{2}{*}{ Yield after cooling (\%) } & \multicolumn{3}{|c|}{ Final yield (\%) } \\
\hline & & & $\mathrm{K} 1-80 \%$ & $\mathrm{~K} 2-70 \%$ & K3 - 60\% \\
\hline Pork & $78.5 \pm 5.3$ & $74.9 \pm 4.4$ & $59.2^{\mathrm{a}} \pm 6.8$ & $55.3^{\mathrm{a}} \pm 3.5$ & $50.8^{\mathrm{a}} \pm 2.8$ \\
\hline Poultry-pork & $84.2 \pm 2.1$ & $82.0 \pm 3.5$ & $65.0^{\mathrm{a}} \pm 3.6$ & $61.2^{\mathrm{a}} \pm 2.9$ & $60.7^{\mathrm{a}} \pm 3.2$ \\
\hline
\end{tabular}

${ }^{a}$ Average values in rows marked with different letters differ significantly at $p \leq 0.05$.

by drying samples at $105^{\circ} \mathrm{C}$ (SUP-65 dryer, Wamed, Warsaw, Poland). The protein content was determined by the Kjeldahl method according to PN-75/A-04018:2002 (Velp Scientifica UDK 129 Distillation Unit, Poland) [19]. The fat content was determined by Soxhlet extraction (Büchi Extraction System B-811, Donserv, Poland) according to PN-ISO 1444:2000 [20]. The salt content was determined using potentiometric methods according to PN-ISO 1841-2:2002 [21], using a 702 SM Titrino (Metrohm AG, Herisau, Switzerland) device.

2.5. Measurement of Water Activity $\left(a_{w}\right)$. Measurement of water activity was carried out using an Aqua Lab CX-2 apparatus (Decagon Devices, Inc., Pullman, USA). The sample was prepared by cutting a flat rectangle from kabanosy, and the analysis was performed at a temperature of $25.0 \pm 1.5^{\circ} \mathrm{C}$, three times for each sample, and the average was taken as a result of the measurement.

2.6. TBARS Indicator Determination. Thiobarbituric acid reactive substances (TBARS) values were determined according to the extraction method of Shahidi [22]. Absorbance was measured at $532 \mathrm{~nm}$ using a spectrophotometer (Hitachi U1100; Gemini bv., Apeldoorn, Netherlands) against a blank containing $5 \mathrm{~mL}$ of 2-thiobarbituric acid (TBA) and $5 \mathrm{~mL}$ of $10 \%$ trichloroacetic acid (TCA). A constant coefficient of 2.34 was employed for converting the absorbance units to TBARS values, which were expressed as $\mathrm{mg}$ malondialdehyde per $\mathrm{kg}$ sample (mg MAD $/ \mathrm{kg}$ ).

2.7. Measurement of Texture-Shear Force. Measurement of the shear force was performed using a ZWICKI 1120 endurance apparatus (Zwick, Ulm, Germany). Warner-Bratzler's device equipped with a flat knife was used for this purpose. The maximum shear force $F_{\max }$ was read out at a head shift of $50 \mathrm{~mm} / \mathrm{min}$. The samples were prepared directly before tests by cutting the kabanosy into $10 \mathrm{~cm}$ sections and subjecting them to 30 minutes of conditioning at room temperature. The measurements were taken at three points on each of the prepared sections, for three different bars from each variant of kabanosy. The results were then averaged.

2.8. Sensory Evaluation. The sensory quality of kabanosy after the drying process in chambers with different levels of humidity was assessed using a 10-point intensity scale for such sensory characteristics as surface color, hardness, aroma, and taste. However, overall acceptability was assessed on a hedonic scale (where 0 points corresponded to unacceptable and a 10-point evaluation as very desirable). The evaluation was conducted by a trained 10 -person team according to PN-ISO 4121:1998 [23]. Kabanosy prior to the assessment were conditioned for half an hour at room temperature.

2.9. Statistical Analysis of the Results. The results were subjected to statistical analysis using ANOVA analysis and a detailed Tukey's HSD test, at a significance level of $\alpha=0.05$. Statistica ver. 10 PL (StatSoft, Inc., Tulsa, USA) was used. The effect of air relative humidity in the drying chamber on yield and on selected quality features of pork and poultry-pork kabanosy was determined.

\section{Results and Discussion}

3.1. Yield of Kabanosy. The yields of kabanosy at different stages of the production process are shown in Table 1 . In the case of both pork and poultry-pork kabanosy, there was no significant $(p>0.05)$ effect derived from air relative humidity on the final yield of these products (Table 1). Dried sausages can lose up to $30 \%$ of their weight throughout the production process and such sausages in the US market are considered to be "moderately" dry products. In contrast, dry sausages are those that are characterized by a $40 \%$ weight loss [24]. The weight loss of the product is faster in the case of a product dried at lower relative air humidity [25]. The tendency observed in this study was, therefore, consistent with the literature data. The period of drying of kabanosy in the chamber with $80 \%$ humidity (yield below $68 \%$, as required by TGS) was considerably longer in comparison with the drying time of the kabanosy under a humidity of 70 and $60 \%$. The use of lower relative humidity in the drying process reduced the duration of the process by $50 \%$; however, this may result in lower product yield. The observed average 10 -percentage point difference in the yield of pork kabanosy dried at 80 and $60 \%$ relative air humidity was caused not only by the varying relative air humidity in the chamber but also by the varied duration of the process. The different drying dynamics of both types of kabanosy suggest the need for the selection of optimum drying conditions in terms of raw material composition.

3.2. $L^{*} a^{*} b^{*}$ Color Components of Kabanosy. The results of $L^{*}, a^{*}$ and $b^{*}$ color component measurement on the surface and cross sections of kabanosy are summarized in Table 2. A reduction of color component $L^{*}$, and thus the lightness of the surface after the drying process, was noted in pork kabanosy. The lowest value for this component was observed in the case of kabanosy subjected to drying in a chamber with a relative air humidity of $60 \%$. The effect of different relative air humidities in terms of the color lightness on the 


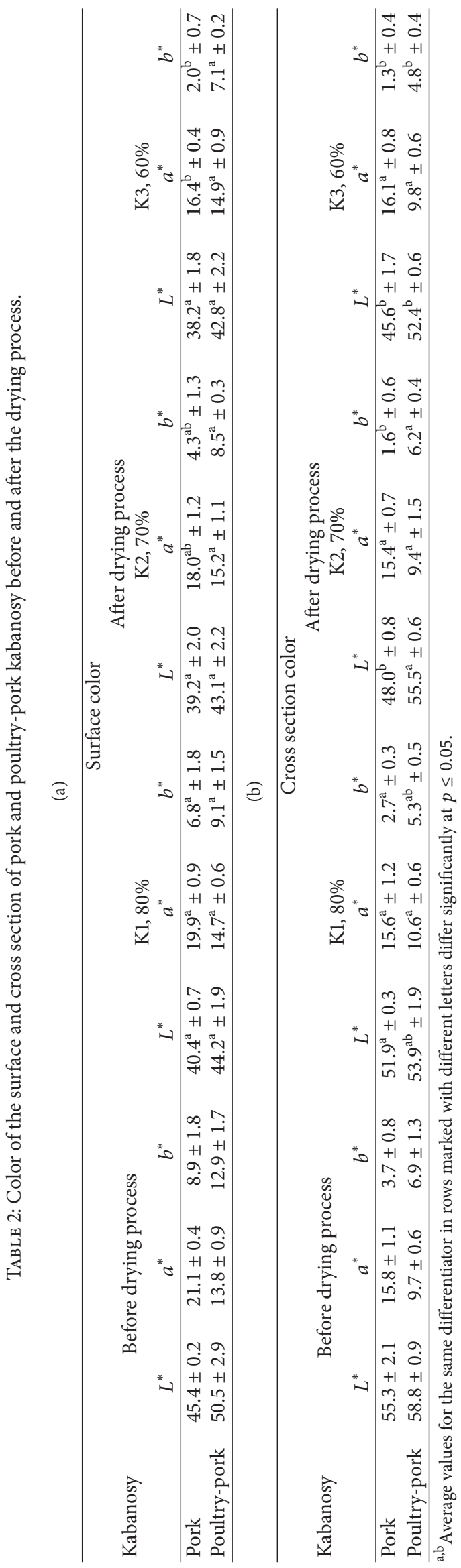


surface of pork kabanosy was not significant $(p>0.05)$. Similar relationships were found for poultry-pork kabanosy (Table 2). According to De Maere et al. [26], reduction of the $L^{*}$ component values during the drying process may result from the reduction of water content in the product.

For both the pork and poultry-pork kabanosy, a decrease in the values of the $a^{*}$ and $b^{*}$ color components was observed during the drying process in chambers with different relative air humidity compared to the kabanosy before the drying process. This applies to both the color of the bar and the cross section of the products. There was a tendency for $a^{*}$ and $b^{*}$ values to be lower with a decrease in relative air humidity in the drying chamber. Pork kabanosy dried with an relative air humidity of $60 \%$ were characterized by significantly $(p<$ 0.05 ) lower values for components $a^{*}$ and $b^{*}$ than kabanosy dried at $80 \%$ humidity (Table 2). In contrast, for the poultrypork kabanosy, drying relative air humidity had no significant $(p>0.05)$ effect on the values of those components (Table 2).

Measurements of color components $L^{*}, a^{*}$, and $b^{*}$ were also taken on the cross sections of kabanosy. The color on the cross sections of kabanosy dried with a relative air humidity of $70 \%$ and $60 \%$ was characterized by significantly lower values for component $L^{*}$ compared to the values obtained on the cross sections of kabanosy dried at $80 \%$ humidity (Table 2). In the case of poultry-pork kabanosy, a significant $(p<0.05)$ effect of relative air humidity was noted on the lightness of their cross section color; however, this effect was ambiguous. Poultry-pork kabanosy dried in a chamber with a relative air humidity of $60 \%$ were characterized by significantly lower values for component $L^{*}$, and so they were the darkest, compared to kabanosy dried at a humidity of $70 \%$ (Table 2).

Pork kabanosy dried in chambers with a relative air humidity of 70 and $60 \%$ were characterized by significantly $(p<0.05)$ lower levels of yellow color $\left(b^{*}\right)$ in the cross sections of the bar compared to kabanosy dried at a relative air humidity of $80 \%$ (Table 2).

In the case of poultry-pork kabanosy, significant differentiation of this color component was observed between the values determined for the cross section of the product dried at 70 and $60 \%$ of relative air humidity (Table 2).

\subsection{Content of the Basic Chemical Components in Kabanosy.} The average content of basic chemical components in pork kabanosy before the drying process was $52.1 \%$ water content, $24.8 \%$ protein content, $19.6 \%$ fat content, and $3.0 \%$ salt content. During the drying process, as expected, there was a decrease in the water content and increase in the components constituting the dry matter of the product. Olivares et al. [27] indicate that the concentration of protein and fat in the product during the drying process is mainly due to the water content decrease resulting from weight loss. The highest average values for protein (29.5\%), fat (23.5\%), and salt (3.6\%) content were found in the case of drying of the pork kabanosy in a chamber with $60 \%$ relative air humidity. Despite the 10 percentage point differences in the yield of products dried at $80 \%$ and $60 \%$ of relative air humidity, no significant differences $(p>0.05)$ were found in the chemical composition of kabanosy dried in chambers with different relative air humidity. This could be due to significant differences in the process of drying in the various research series, as evidenced by, among others, high standard deviations.

In the case of poultry-pork kabanosy, a decrease in water content was observed from $53.1 \%$ before the drying process to $45.8 \%$ after drying in a relative air humidity of $60 \%$. Protein, fat, and salt content changed from 21.7, 21.9, and $2.7 \%$, respectively, before the drying process to $25.4,25.6$, and $3.1 \%$ after drying in the chamber with $60 \%$ relative air humidity. Also in this case, there were no significant $(p>$ 0.05 ) differences of chemical composition of poultry-pork kabanosy dried in chambers of different relative air humidity (data not shown).

According to European Parliament and Council Regulation (EU) number 1044/2011 [10], kabanosy should be characterized by the following chemical composition: protein content of at least $15 \%$, water up to $60 \%$, fat up to $35 \%$, and salt maximum $3.5 \%$. The poultry-pork kabanosy produced in this study, irrespective of the drying conditions, met all the above requirements. In the case of pork kabanosy, only a slight excess of or the average salt content was found in products dried at $60 \%$ relative air humidity.

3.4. Water Activity $\left(a_{w}\right)$, TBARS Indicator Value, and Texture of Kabanosy. The water activity of both pork and poultrypork kabanosy decreased with a decrease in relative air humidity in the drying chamber (Table 3 ). There was no significant $(p>0.05)$ effect of drying air humidity on water activity in pork kabanosy. Poultry-pork products dried at $60 \%$ humidity were characterized by a significantly $(p<0.05)$ lower water activity than those dried at 70 and $80 \%$ humidity. Also in the studies presented by Collell et al. [1], a relationship was demonstrated between the fall in $a_{w}$ and water content during the drying process.

In the present study, there was no significant $(p>0.05)$ effect of air relative humidity on the value of the TBARS indicator in the case of pork and poultry-pork kabanosy (Table 3).

There was no significant $(p>0.05)$ effect of air relative humidity on the shear force of either pork or poultry-pork kabanosy. There was only a tendency pointing to an increase in the shear force of kabanosy with a decrease in relative humidity in the drying chamber. According to Arnau et al. [14], the first method to obtain an acceptable texture with a short drying period in dry-cured meat products is to accelerate the drying process by decreasing the relative humidity and increasing the temperature of the drying air. This was not confirmed in our research.

3.5. Sensory Quality of Kabanosy. A reduced relative humidity of the air in the drying chamber did not affect such sensory qualities of pork and poultry-pork kabanosy as hardness, aroma, taste, and overall acceptability (Table 4). A significant $(p<0.05)$ impact on the color of pork kabanosy was noted as a result of the relative air humidity. Kabanosy dried at the relative humidity of $60 \%$ received lower scores for color than kabanosy dried at a humidity of $80 \%$. An opposite trend was observed in the case of the color of poultry-pork kabanosy, but this was not significant (Table 4). Also, some trends in 
TABLE 3: Water activity $\left(a_{w}\right)$ and TBARS indicator values in pork and poultry-pork kabanosy before and after the drying process; shear force value after drying process.

(a)

\begin{tabular}{|c|c|c|c|c|c|c|c|c|}
\hline \multirow{3}{*}{ Kabanosy } & \multicolumn{4}{|c|}{ Water activity } & \multicolumn{4}{|c|}{ TBARS (mg MAD/kg of the product) } \\
\hline & \multirow{2}{*}{$\begin{array}{c}\text { Before drying } \\
\text { process }\end{array}$} & \multicolumn{3}{|c|}{ After drying process } & \multirow{2}{*}{$\begin{array}{c}\text { Before drying } \\
\text { process }\end{array}$} & \multicolumn{3}{|c|}{ After drying process } \\
\hline & & $\mathrm{K} 1,80 \%$ & $\mathrm{~K} 2,70 \%$ & $\mathrm{~K} 3,60 \%$ & & $\mathrm{~K} 1,80 \%$ & $\mathrm{~K} 2,70 \%$ & $\mathrm{~K} 3,60 \%$ \\
\hline Pork & $0.943 \pm 0.007$ & $0.940^{\mathrm{a}} \pm 0.004$ & $0.927^{\mathrm{a}} \pm 0.011$ & $0.919^{a} \pm 0.011$ & $0.54 \pm 0.17$ & $0.50^{\mathrm{a}} \pm 0.11$ & $0.60^{\mathrm{a}} \pm 0.23$ & $0.56^{\mathrm{a}} \pm 0.18$ \\
\hline $\begin{array}{l}\text { Poultry- } \\
\text { pork }\end{array}$ & $0.956 \pm 0.005$ & $0.940^{\mathrm{a}} \pm 0.002$ & $0.935^{\mathrm{a}} \pm 0.004$ & $0.926^{\mathrm{b}} \pm 0.003$ & $0.55 \pm 0.08$ & $0.53^{\mathrm{a}} \pm 0.08$ & $0.55^{\mathrm{a}} \pm 0.12$ & $0.55^{\mathrm{a}} \pm 0.11$ \\
\hline
\end{tabular}

(b)

\begin{tabular}{lcrr}
\hline Kabanosy & \multicolumn{3}{c}{ Shear force $(N)$} \\
& K1, $80 \%$ & After drying process & K2, 70\% \\
\hline Pork & $91.3^{\mathrm{a}} \pm 14.9$ & $99.3^{\mathrm{a}} \pm 6.9$ & $103.4^{\mathrm{a}} \pm 8.0$ \\
Poultry-pork & $83.6^{\mathrm{a}} \pm 17.9$ & $85.5^{\mathrm{a}} \pm 22.9$ & $94.4^{\mathrm{a}} \pm 14.9$ \\
\hline
\end{tabular}

${ }_{\mathrm{a}, \mathrm{b}}$ Average values for the same differentiator in rows marked with different letters differ significantly at $p \leq 0.05$.

TABLE 4: The effect of air relative humidity on the sensory quality characteristics of kabanosy.

\begin{tabular}{|c|c|c|c|c|}
\hline Characteristic (points) & Kabanosy & $\mathrm{K} 1,80 \%$ & $\mathrm{~K} 2,70 \%$ & $\mathrm{~K} 3,60 \%$ \\
\hline \multirow{2}{*}{ Surface color } & Pork & $9.4^{\mathrm{a}} \pm 0.6$ & $8.4^{\mathrm{ab}} \pm 0.3$ & $6.8^{\mathrm{b}} \pm 0.3$ \\
\hline & Poultry-pork & $7.4^{\mathrm{a}} \pm 0.5$ & $8.2^{\mathrm{a}} \pm 0.3$ & $9.26^{\mathrm{a}} \pm 0.3$ \\
\hline \multirow{2}{*}{ Hardness } & Pork & $9.4^{\mathrm{a}} \pm 1.2$ & $8.4^{\mathrm{a}} \pm 0.9$ & $7.2^{\mathrm{a}} \pm 0.6$ \\
\hline & Poultry-pork & $8.8^{\mathrm{a}} \pm 0.2$ & $8.6^{\mathrm{a}} \pm 0.2$ & $9.6^{\mathrm{a}} \pm 1.0$ \\
\hline \multirow{2}{*}{ Aroma } & Pork & $6.8^{\mathrm{a}} \pm 0.8$ & $6.8^{\mathrm{a}} \pm 0.7$ & $6.6^{\mathrm{a}} \pm 0.3$ \\
\hline & Poultry-pork & $8.2^{\mathrm{a}} \pm 0.6$ & $8.2^{\mathrm{a}} \pm 0.8$ & $8.0^{\mathrm{a}} \pm 0.9$ \\
\hline \multirow{2}{*}{ Taste } & Pork & $7.4^{\mathrm{a}} \pm 0.3$ & $7.2^{\mathrm{a}} \pm 0.8$ & $6.2^{\mathrm{a}} \pm 0.8$ \\
\hline & Poultry-pork & $7.4^{\mathrm{a}} \pm 0.6$ & $8.6^{\mathrm{a}} \pm 0.5$ & $8.0^{\mathrm{a}} \pm 0.5$ \\
\hline \multirow{2}{*}{ Overall acceptability } & Pork & $6.2^{\mathrm{a}} \pm 0.5$ & $6.0^{\mathrm{a}} \pm 0.5$ & $7.2^{\mathrm{a}} \pm 0.9$ \\
\hline & Poultry-pork & $6.4^{\mathrm{a}} \pm 0.8$ & $6.6^{\mathrm{a}} \pm 1.4$ & $6.8^{\mathrm{a}} \pm 1.4$ \\
\hline
\end{tabular}

a,b Average values for the same differentiator in rows marked with different letters differ significantly at $p \leq 0.05$.

changes in the scores given in the evaluation of hardness and taste of kabanosy were observed. In the case of pork kabanosy, scores given for these discriminants were lower with the decrease in relative humidity; and in the case of poultry-pork kabanosy, marks were higher (Table 4). This confirms the need for a separate examination of the effect of humidity in the drying chamber, depending on the type of raw material used in kabanosy production.

\section{Conclusion}

Pork kabanosy produced at differentiated drying relative air humidities met the requirements for the recipe for traditional specialty guaranteed (TSG) regarding the content of basic chemical components, water, protein and fat, and the assumed final yield; in the case of the salt content, these assumptions were only met in the case of the product dried in air at 70 and $80 \%$ relative humidity. TSG assumptions regarding the chemical composition were also fulfilled by poultry-pork kabanosy, regardless of relative air humidity in the chamber. The final yield of the products was proportional to the humidity prevailing in the drying chamber, but this was not significantly differentiated. Kabanosy dried in air of $60 \%$ humidity were thus characterized by the lowest final yield; and, moreover, the duration of drying in this case was the shortest. No significant effect of drying relative air humidity was found on the value of the TBARS indicator in the case of pork or poultry-pork kabanosy; however, reduced water activity and water content were observed with a decrease in air relative humidity and analogically an increase was observed in protein and fat content in the products. After the drying process, the products were darker both on the surface and in cross section (a lower value for component $L^{*}$ ) than before the process. Also, relative air humidity in the drying chamber affected the color components of kabanosy. The changes in the contents of particular chemical component in pork kabanosy compared to poultry-pork ones point to the different dynamics of the drying process of both types of kabanosy and the need for the selection of optimum drying conditions in terms of raw material composition.

Differentiation in relative air humidity in the drying chambers affected the dynamics of changes, mainly in terms of the color parameters and water activity of produced kabanosy. Moreover, pork kabanosy dried at the relative 
humidity of $60 \%$ received lower scores for color than kabanosy dried at a humidity of $80 \%$. The results obtained in this study indicate the possibility of shortening the drying process by $50 \%$, together with the reduction of humidity in the drying chamber from 80 to $60 \%$. In turn, the economic effect of the lower humidity should be examined under production plant conditions.

\section{Conflicts of Interest}

The authors declare that there are no conflicts of interest regarding the publication of this paper.

\section{References}

[1] C. Collell, P. Gou, J. Arnau, I. Muñoz, and J. Comaposada, "NIR technology for on-line determination of superficial $\mathrm{a}_{w}$ and moisture content during the drying process of fermented sausages," Food Chemistry, vol. 135, no. 3, pp. 1750-1755, 2012.

[2] W.-W. Ren, A. E.-D. A. Bekhit, F. Li et al., "Physicochemical properties of pastirma from horse meat, beef, mutton and pork," Journal of Food Quality, vol. 38, no. 5, pp. 369-376, 2015.

[3] G. Tabanelli, F. Coloretti, C. Chiavari, L. Grazia, R. Lanciotti, and F. Gardini, "Effects of starter cultures and fermentation climate on the properties of two types of typical Italian dry fermented sausages produced under industrial conditions," Food Control, vol. 26, no. 2, pp. 416-426, 2012.

[4] M. J. Fraqueza, "Antibiotic resistance of lactic acid bacteria isolated from dry-fermented sausages," International Journal of Food Microbiology, vol. 212, pp. 76-88, 2015.

[5] A. Berardo, B. Devreese, H. De Maere et al., "Actin proteolysis during ripening of dry fermented sausages at different $\mathrm{pH}$ values," Food Chemistry, vol. 221, pp. 1322-1332, 2017.

[6] F. Toldrá and M. Reig, "Innovations for healthier processed meats," Trends in Food Science and Technology, vol. 22, no. 9, pp. 517-522, 2011.

[7] E. Muguerza, O. Gimeno, D. Ansorena, and I. Astiasarán, "New formulations for healthier dry fermented sausages: a review," Trends in Food Science and Technology, vol. 15, no. 9, pp. 452457, 2004

[8] Z. Pieniak, W. Verbeke, F. Vanhonacker, L. Guerrero, and M. Hersleth, "Association between traditional food consumption and motives for food choice in six European countries," Appetite, vol. 53, no. 1, pp. 101-108, 2009.

[9] M. Dušková, J. Kameník, O. Šedo et al., "Survival and growth of lactic acid bacteria in hot smoked dry sausages (non-fermented salami) with and without sensory deviations," Food Control, vol. 50, pp. 804-808, 2015.

[10] Commission Regulation 1044/2011, "European Parliament and Council Regulation (EU) No 1044/2011 of 19 October 2011 recording in the register of traditional specialties guaranteed [Kabanosy (TSG)]," Official Journal of the European Communities, vol. L 275/16, 2011.

[11] A. del Olmo, J. Calzada, and M. Nuñez, "Lipolysis, lipid peroxidation and texture of Serrano ham processed under different ripening temperature conditions," International Journal of Food Science and Technology, vol. 51, no. 8, pp. 1793-1800, 2016.

[12] K. Naidoo and D. Lindsay, "Survival of Listeria monocytogenes, and enterotoxin-producing Staphylococcus aureus and Staphylococcus pasteuri, during two types of biltong-manufacturing processes," Food Control, vol. 21, no. 7, pp. 1042-1050, 2010.
[13] F. Toldrá, "The role of muscle enzymes in dry-cured meat products with different drying conditions," Trends in Food Science and Technology, vol. 17, no. 4, pp. 164-168, 2006.

[14] J. Arnau, X. Serra, J. Comaposada, P. Gou, and M. Garriga, "Technologies to shorten the drying period of dry-cured meat products," Meat Science, vol. 77, no. 1, pp. 81-89, 2007.

[15] B. A. Nummer, J. A. Harrison, M. A. Harrison, P. Kendall, J. N. Sofos, and E. L. Andress, "Effects of preparation methods on the microbiological safety of home-dried meat jerky," Journal of Food Protection, vol. 67, no. 10, pp. 2337-2341, 2004.

[16] M. Hersleth, V. Lengard, W. Verbeke, L. Guerrero, and T. Næs, "Consumers' acceptance of innovations in dry-cured ham: impact of reduced salt content, prolonged aging time and new origin," Food Quality and Preference, vol. 22, no. 1, pp. 31-41, 2011.

[17] A. Al-Nehlawi, S. Guri, B. Guamis, and J. Saldo, "Synergistic effect of carbon dioxide atmospheres and high hydrostatic pressure to reduce spoilage bacteria on poultry sausages," $L W T$ Food Science and Technology, vol. 58, no. 2, pp. 404-411, 2014.

[18] Polish Committee for Standardization, Polish Standard PNISO 1442:2000. Meat and Meat Products. Determination of Moisture Content-Reference Method, Polish Committee for Standardization, Warsaw, Poland, 2000.

[19] Polish Committee for Standardization, Polish Standard PN-A-04018:1975/Az3:2002. Agricultural Food Products-Determination of Nitrogen by The Kjeldahl Method and Expressing as Protein, Polish Committee for Standardization, Warsaw, Poland, 2002.

[20] Polish Committee for Standardization, Polish Standard PNISO 1444:2000. Meat and Meat Products. Determination of Free Fat Content, Polish Committee for Standardization, Warsaw, Poland, 2000.

[21] Polish Committee for Standardization, Polish Standard PN-ISO 1841-2:2002. Meat and Meat Products. Determination of Chloride Content-Part 2: Potentiometric Method, Polish Committee for Standardization, Warsaw, Poland, 2002.

[22] F. Shahidi, "The 2-thiobarbituric acid (TBA) methodology for the evaluation of warmed-over flavour and rancidity in meat products," in Proceedings of the 36th ICoMST, pp. 1008-1015, Havana, Cuba, 1990.

[23] Polish Committee for Standardization, Polish Standard PN-ISO 4121: 1998. SEnsory Analysis. Methodology. Evaluation of Food Products Using The Method of Scaling, Polish Committee for Standardization, Warsaw, Poland, 1998.

[24] R. Maddock, "US Products-Dry Sausage," in Handbook of Fermented Meat and Poultry, pp. 295-300, Wiley-Blackwell, 2nd edition, 2014.

[25] J. Arnau, P. Gou, and J. Comaposada, "Effect of the relative humidity of drying air during the resting period on the composition and appearance of dry-cured ham surface," Meat Science, vol. 65, no. 4, pp. 1275-1280, 2003.

[26] H. De Maere, I. Fraeye, E. De Mey et al., "Formation of naturally occurring pigments during the production of nitrite-free dry fermented sausages," Meat Science, vol. 114, pp. 1-7, 2016.

[27] A. Olivares, J. L. Navarro, A. Salvador, and M. Flores, "Sensory acceptability of slow fermented sausages based on fat content and ripening time," Meat Science, vol. 86, no. 2, pp. 251-257, 2010. 

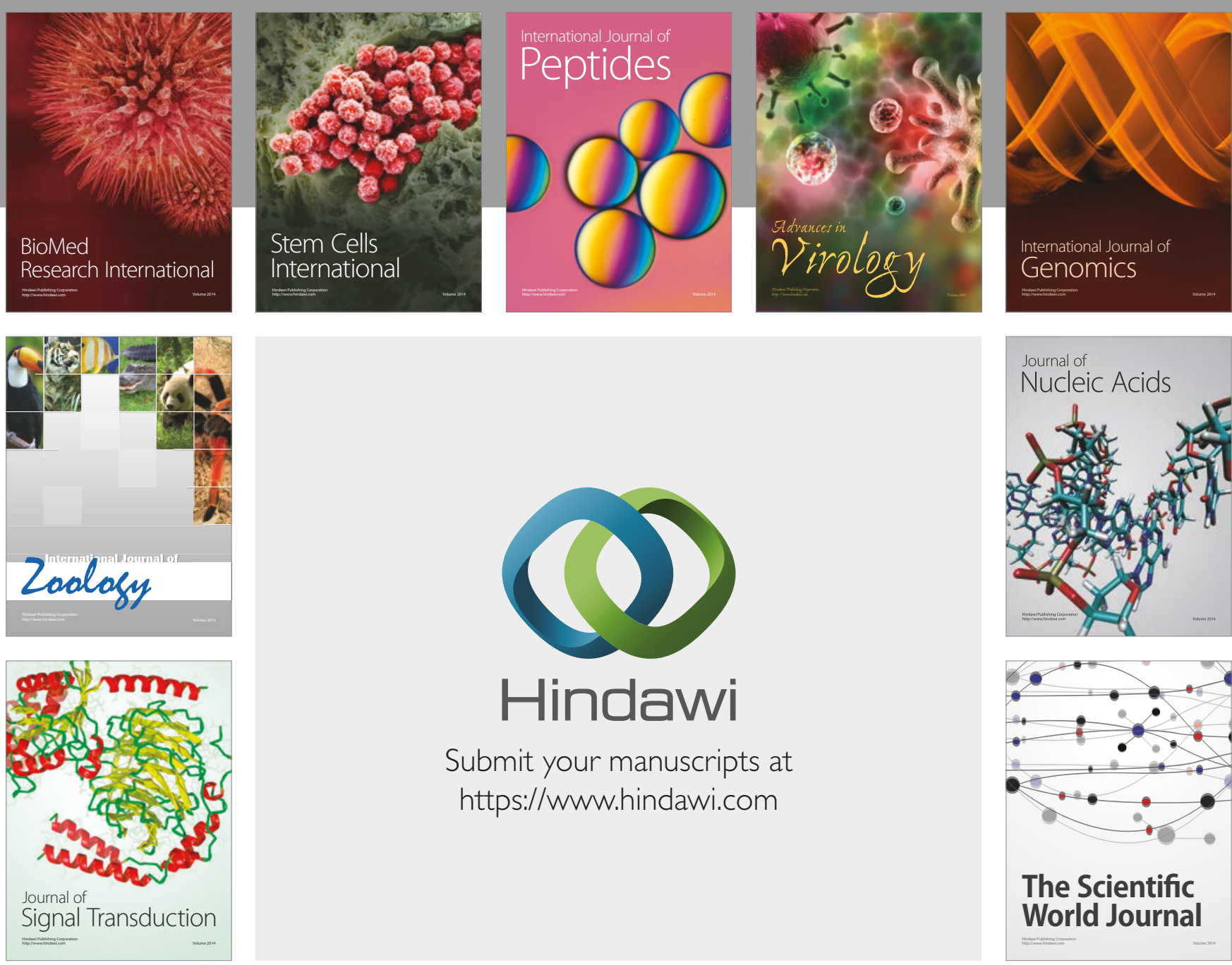

Submit your manuscripts at

https://www.hindawi.com
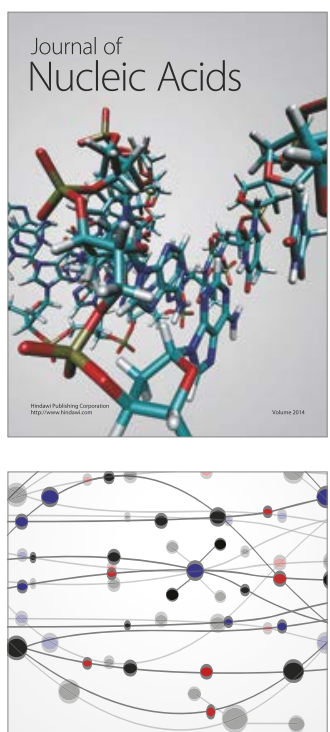

The Scientific World Journal

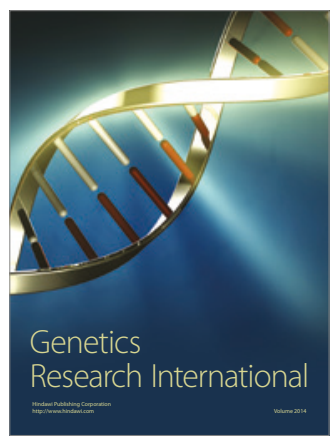

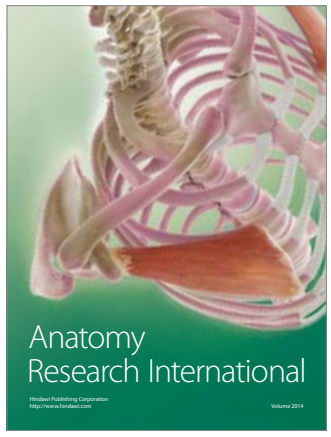

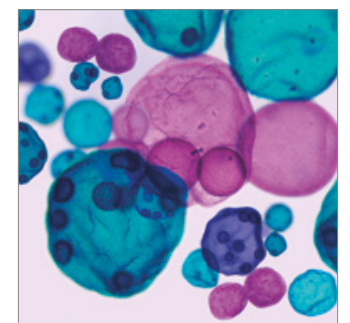

International Journal of Microbiology
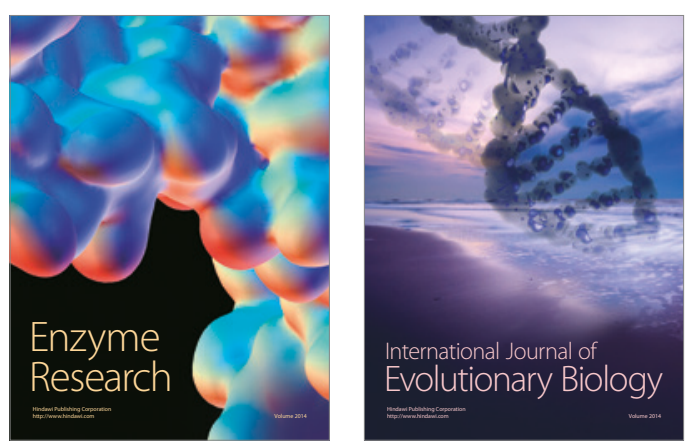
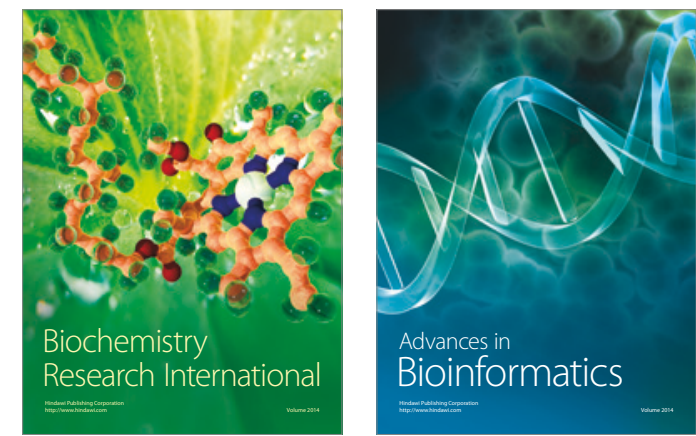

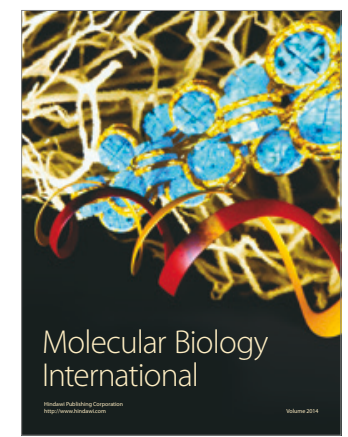

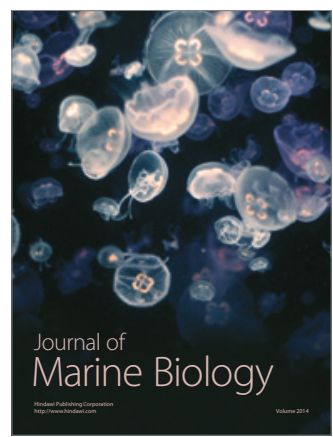

